RADIN, B.; REISSER JÚNIOR, C.; MATZENAUER, R.; BERGAMASCHI, H. Crescimento de cultivares de alface conduzidas em estufa e a campo. Horticultura Brasileira, Brasília, v.22, n.2, p.178-181, abril-junho 2004.

\title{
Crescimento de cultivares de alface conduzidas em estufa e a campo
}

\author{
Bernadete Radin $^{1}$; Carlos Reisser Júnior ${ }^{2}$; Ronaldo Matzenauer ${ }^{1}$; Homero Bergamaschi ${ }^{3}$ \\ ${ }^{1}$ FEPAGRO/SCT, Rua Gonçalves Dias, 570, 90130-060 Porto Alegre-RS; ${ }^{2}$ Embrapa Clima Temperado, C. Postal 403, 96001-970 \\ Pelotas-RS; ${ }^{3}$ UFRGS, C. Postal 776, 91501-970 Porto Alegre-RS. E-mail: radin@ffepagro.rs.gov.br
}

\section{RESUMO}

Alguns indicadores de crescimento das cultivares de alface Verônica, Marisa e Regina foram analisados, através de um experimento em estufa de plástico e a campo, de 15/04 a 03/06/99, na FEPAGRO, em Eldorado do Sul (RS). As amostragens das plantas iniciaram-se uma semana após o transplante e prosseguiram (semanalmente) até o final do ciclo da cultura. As plantas cultivadas em estufa, apresentaram aumento na massa de matéria fresca e seca foliar, na área foliar e área foliar específica e no número de folhas. Além disso, o ciclo da cultura foi reduzido, quando comparada àquela cultivada a campo. As cultivares não apresentaram diferença entre si quando cultivadas em ambiente de estufa, mas, em condições de campo, a cultivar Regina apresentou maior número de folhas e maior índice de área foliar do que as cultivares Marisa e Verônica.

Palavras-chave: Lactuca sativa L., estufa de plástico, matéria seca, matéria fresca.

\begin{abstract}
Growth of lettuce cultivars in greenhouse and the field

The growth of lettuce cvs. Veronica, Marisa and Regina was analised through an experiment carried out under plastic greenhouse and under field conditions, from April $15^{\text {th }}$ to June $03^{\text {rd }} 1999$, in Eldorado do Sul, Rio Grande do Sul State, Brazil. Sampling of plants started one week after transplanting and proceeded until the end of the plant cycle on a weekly basis. The lettuce cultivated under greenhouse presented more fresh and dry mass, leaf area, specific leaf area and greater number of leaves. In addition, plants cultivated under greenhouse presented a shorter cycle when compared to the plants cultivated in field conditions. The cvs. did not show any difference when cultivated under greenhouse environment, but, in field conditions, the cv. Regina presented a larger number of leaves and a larger leaf area index than the cultivars Marisa and Veronica.
\end{abstract}

Keywords: Lactuca sativa L., plastic greenhouse, fresh matter, dry matter.

\section{(Recebido para publicação em 6 de janeiro de 2003 e aceito em 5 de janeiro de 2004)}

A alface encontra-se entre as cinco hortaliças de maior movimento financeiro na CEASA (RS), sendo somente menor do que tomate, batata, cebola e cenoura. É a segunda maior em termos de volume comercializado dentre as folhosas, apresentando um montante de 7,72 t comercializadas em 2001 (CEASA, 2002).

No estado do Rio Grande do Sul, a alface é produzida durante todo o ano, existindo, no entanto, dois períodos com condições climáticas pouco favoráveis: o verão, quando ocorrem elevadas temperatura do ar e radiação solar, o que favorece o pendoamento precoce das plantas; e o inverno com ocorrência de baixas temperaturas e precipitações pluviais prolongadas que podem retardar o crescimento e danificar as plantas (Segovia et al., 1997).

A alface, cultura de clima temperado, é melhor adaptada a temperaturas baixas do que às altas. A máxima tolerável pela planta fica em torno de $30^{\circ} \mathrm{C}$ e a mínima situa-se em torno de $6^{\circ} \mathrm{C}$, para a maioria das cultivares. É uma planta que exige grandes amplitudes térmicas entre o dia e a noite. A umidade relativa mais adequada ao bom desenvolvimento da alface, varia de 60 a $80 \%$, mas em determinadas fases de seu ciclo apresenta melhor desempenho com valores inferiores a $60 \%$. Umidade muito elevada favorece a ocorrência de doenças, fato que constitui um dos problemas da cultura produzida em estufa plástica (Cermeño, 1990).

Comparando o crescimento e desenvolvimento de algumas cultivares de alface durante o inverno, em estufa e a campo, Segovia et al. (1997) mostraram que o número de folhas emitidas na estufa apresentou tendência de maiores valores. Por outro lado, o acúmulo de massa seca apresentou velocidade semelhante, nos dois ambientes, embora com valores menores a campo. Também foram verificadas taxas de crescimento maiores no interior de estufas, resultando em produção mais precoce e de melhor qualidade do que aquela obtida em ambiente não protegido.

Na análise dos parâmetros de crescimento e desenvolvimento foi observado que o cultivo em estufa influencia a velocidade de crescimento da planta. Os parâmetros da massa seca foliar e do índice de área foliar indicam que a massa específica das folhas é menor no interior da estufa. Isso significa que no interior da estufa as folhas se expandem mais rapidamente, o que pode ser atribuído, principalmente, aos teores mais elevados da umidade relativa do ar existentes no interior da estufa. Essa característica favorece a aparência visual do produto, mas é negativa do ponto de vista da resistência ao transporte e da conservação pós-colheita (Tibbits e Bottemberg, 1976).

Segundo Dantas e Escobedo (1998), a taxa de crescimento relativo (TCR), expressa em função da variação da massa seca, no verão foi aproximadamente 9\% superior na parte externa do que a interna da estufa. Entretanto, no inverno, a TCR foi maior dentro da estufa plástica, em torno de $20 \%$. De maneira geral, a TCR média do inverno superou a TCR média do verão em $10 \%$. A taxa de crescimento da cultura (TCC) que correlaciona o índice de área foliar com a taxa de assimilação líquida, expressando a produção de massa seca em relação à área cultivada, geralmente foi maior no verão, com superioridade de 
aproximadamente $69 \%$ nos ambientes protegidos e de $60 \%$ na parcela externa, refletindo demasiadamente no rendimento final da cultura.

A alface é uma folhosa extremamente sensível às variações meteorológicas e ao excesso de chuva. Por este motivo realizou-se um experimento em ambiente de estufa e a campo, com o objetivo de analisar alguns indicadores de crescimento das cultivares de alface Verônica, Marisa e Regina, em Eldorado do Sul (RS).

\section{MATERIAL E MÉTODOS}

O experimento foi conduzido na FEPAGRO em Eldorado do Sul (latitude $30^{\circ} 05^{\prime} \mathrm{S}$; longitude $51^{0} 39^{\prime} \mathrm{W}$; altitude $10 \mathrm{~m}$ ) na região climática da Depressão Central do Rio Grande do Sul. O clima da região é "Cfa" subtropical úmido de verão quente. A precipitação média anual é de $1440 \mathrm{~mm}$ e a evapotranspiração de referência (Método de Penman) é de $1235 \mathrm{~mm}$ na média anual (Bergamaschi e Guadagnin, 1990).

O experimento foi conduzido a campo e em estufa plástica tipo pampeana, com cobertura em arco, possuindo $24 \mathrm{~m}$ de comprimento e $10 \mathrm{~m}$ de largura, coberta com polietileno transparente de $150 \mu \mathrm{m}$ de espessura. Na parte lateral da estufa havia tela antiinsetos de coloração branca. Foram utilizadas três cultivares de alface: Regina (lisa), Verônica e Marisa (crespas). O espaçamento utilizado foi de $30 \mathrm{~cm}$ entre linhas e $30 \mathrm{~cm}$ na linha.

A semeadura foi realizada em bandejas de poliestireno expandido, com 128 células, em 17/03/99. O substrato utilizado foi à base de compostagem de pinus. Em 15/04 foi realizado o transplante das mudas para os canteiros nos dois ambientes. As amostragens das plantas iniciaram uma semana após o transplante (22/04), e continuaram semanalmente até o final do ciclo da cultura (20/05 em estufa e 03/06 a campo). Foram utilizados tensiômetros de manômetros de mercúrio (construídos) para o monitoramento do potencial matricial da água no solo, para que não houvesse restrição hídrica. A irrigação foi realizada por gotejamento, através de mangueiras com gotejadores integrados tipo labirinto. Não foi aplicada adu- bação e nem defensivos durante o ciclo de desenvolvimento da cultura.

A abertura das cortinas da estufa era realizada em torno das 8 horas e o fechamento por volta das 18 horas, com exceção dos dias em que havia muito vento, nos quais as cortinas eram fechadas para evitar danos às plantas e/ou à cobertura da estufa.

Durante o período experimental, foram coletadas duas plantas por parcela e em cinco repetições. Analisou-se a área foliar (AF), massa de matéria fresca aérea (MMF), massa de matéria seca aérea (MMS), número de folhas (NF), área foliar específica (AFE), taxa de crescimento absoluto (TCA) e percentagem de matéria seca.

A área foliar foi medida com a ajuda do um integrador de área foliar LICOR (modelo LI 3000). A determinação da massa de matéria fresca aérea (MMF) foi realizada pela pesagem das folhas logo após a colheita das mesmas. A determinação da massa de matéria seca aérea (MMS) foi realizada secando-se as folhas das plantas em estufa ventilada a $75^{\circ} \mathrm{C}$, até peso constante, realizando-se posteriormente a pesagem das mesmas.

A área foliar específica (AFE) foi calculada da seguinte maneira:

$$
A F E=\frac{A F}{M M S}\left(\mathrm{~cm}^{2} \mathrm{~g}^{-1}\right)
$$

A taxa de crescimento absoluto (TCA) foi calculada pela seguinte expressão:

$$
T C A=\frac{P_{2}-P_{1}}{T_{2}-T_{1}}\left(\mathrm{~g} \mathrm{~m}^{-2} \mathrm{dia}^{-1}\right)
$$

em que $P_{2}-P_{1}$ é a diferença de massa de matéria seca $(\mathrm{g})$, em determinada área, e $T_{2}-T_{1}$ é o intervalo de tempo (dias) entre as duas amostragens.

Os resultados foram avaliados pela análise de variância tendo sido utilizado o delineamento de blocos casualizados com cinco repetições, sendo cada bloco constituído de três parcelas de vinte plantas.

Para a caracterização das condições meteorológicas dos ambientes no interior e no exterior da estufa utilizou-se dois termohigrógrafos (marca Fuess): um localizado na parte central da estufa e outro a campo a 1,2 $\mathrm{m}$ acima da superfície do solo. De maneira geral, a temperatura no interior da estufa foi, no máximo, $2^{\circ} \mathrm{C}$ superior à observada a campo.

\section{RESULTADOS E DISCUSSÃO}

A análise da evolução semanal da massa de matéria fresca (MMF), das folhas das cultivares de alface Regina, Marisa e Verônica nos dois ambientes indicou que o ambiente exerce influência no desenvolvimento das plantas, ou seja, as plantas produzidas em ambientes protegidos, apresentaram maior produção de matéria fresca (Figura 1). Este aspecto é evidenciado pela menor percentagem de matéria seca existente nas folhas das plantas cultivadas no interior da estufa e também pela maior área foliar (Figura 2). No momento da colheita, as plantas cultivadas fora da estufa apresentaram mais de $6 \%$ de matéria seca, enquanto que as cultivadas em estufa apresentaram em torno de 3\%. Isto mostra que as plantas cultivadas em estufa apresentaram-se mais hidratadas, o que as torna mais tenras e com melhor aspecto visual.

Não foi observada diferença significativa entre as cultivares estudadas no que se refere à produção de matéria fresca das folhas da alface no cultivo em estufa. No entanto, no cultivo em condições de campo, a variedade Marisa apresentou valores significativamente menores quando comparada às demais (Tabela 1 e Figura 1A).

Observou-se que, no interior da estufa, houve antecipação na colheita, sendo esta realizada aos 35 DAT. Neste período as plantas cultivadas a campo ainda não haviam se desenvolvido plenamente, apresentando menor MMF e MMS (Figura 1). A antecipação da colheita da alface no cultivo em estufa também foi verificada por Segovia et al. (1997) e Dantas e Escobedo (1998).

Também analisou-se as diferenças entre as cultivares dentro de cada ambiente, ao longo de todo o ciclo da cultura. Os resultados mostraram que, em estufa, a MMS entre as cultivares não se diferenciaram entre si. A campo, as cultivares se diferenciaram somente nas duas últimas semanas antes da colheita (Figura 1B), sendo a cultivar Marisa inferior às demais. 
Tabela 1. Massa de matéria fresca foliar (MMF), massa de matéria seca foliar (MMS), área foliar (AF) e número de folhas (NF) da cultura da alface, observados no dia da colheita. Eldorado do Sul (RS), FEPAGRO, 1999.

\begin{tabular}{|c|c|c|c|c|c|c|c|c|}
\hline \multirow{2}{*}{ Cultivar } & \multicolumn{2}{|c|}{$\operatorname{MMF}\left(\mathrm{g} \mathrm{m}^{-2}\right)$} & \multicolumn{2}{|c|}{ MMS $\left(\mathrm{g} \mathrm{m}^{-2}\right)$} & \multicolumn{2}{|c|}{$\operatorname{AF}\left(m^{-2} m^{-2}\right)$} & \multicolumn{2}{|c|}{ NF (planta-1) } \\
\hline & Estufa & Campo & Estufa & Campo & Estufa & Campo & Estufa & Campo \\
\hline$\overline{R e g i n a}$ & 2021,4 & 856,8 & 67,6 & 56,2 & 4,48 & 1,88 & 38,1 & 30 \\
\hline Marisa & 2253,5 & 562,3 & 71,3 & 40,3 & 3,73 & 0,94 & 22,2 & 15,4 \\
\hline Verônica & 2354,8 & 850,2 & 79,2 & 55,7 & 3,94 & 1,28 & 21,7 & 16,5 \\
\hline Média & 2215,2 & 758,3 & 72,7 & 50,7 & 4,01 & 1,37 & 27,3 & 20,6 \\
\hline$\overline{C V}(\%)$ & 29,0 & 17,3 & 19,7 & 13,5 & 21,7 & 13,9 & 11,8 & 6,7 \\
\hline
\end{tabular}

*Médias seguidas de mesma letra, na coluna, não diferem entre si, pelo teste de Tukey, a 5\% de probabilidade.

O ambiente também influenciou no número de folhas produzidas por planta (Figura 3A e Tabela 1). As alfaces, quando cultivadas em estufa, apresentaram um número final de folhas maior do que as cultivadas a campo. Segundo Hermes et al. (2001) a variedade de alface Regina necessita de 45,1 GD (graus-dia) para a emissão de uma nova folha. Como no ambiente de estufa havia maior temperatura durante o período do experimento, pode-se inferir que houve maior soma de GD, o que provocou aumento no número de folhas das três cultivares no ambiente da estufa. Além disso, a temperatura exerce efeito significativo na taxa de aparecimento de folhas em diversas espécies de plantas. Em Cowpea (Vigna unguiculata L.) por exemplo, o aumento de temperatura acelera o aparecimento de folhas (Craufurd et al., 1997).

Também observou-se diferenças no número de folhas entre as cultivares estudadas, ou seja, a variedade Regina apresentou maior número de folhas que as cultivares Verônica e Marisa, as quais não apresentaram diferença entre si (Figura $3 \mathrm{~A}$ e Tabela 1). Também é importante observar que a variedade Regina, cultivada a campo, apresentou maior número de folhas que as cultivares Marisa e Verônica cultivadas no interior da estufa. Isto é um indicativo de que a variedade Regina apresenta melhor adaptação ao ambiente e/ou menor necessidade de graus dia, do que as outras cultivares, para emissão de novas folhas.

O ambiente da estufa teve influência no estabelecimento da superfície foliar da alface, fazendo com que as cultivares apresentassem aumentos significativos do índice de área foliar em relação ao cultivo a campo, desde a pri-

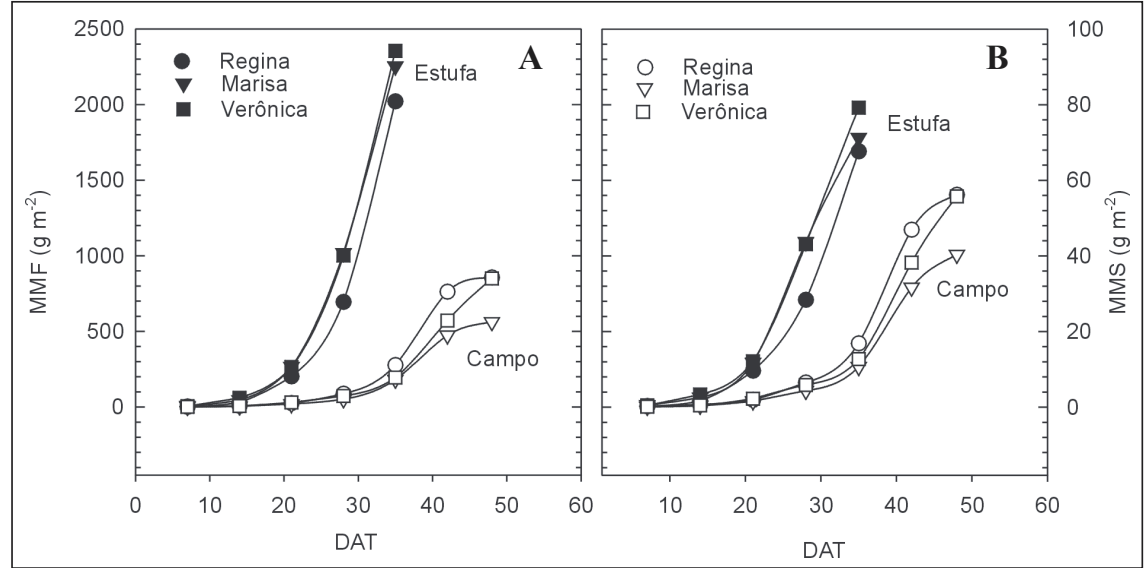

Figura 1. Massa de matéria fresca foliar (MMF) (A) e massa de matéria seca foliar (MMS) (B) de três cultivares de alface cultivadas em estufa e a campo em função de dias após o transplante (DAT). Eldorado do Sul (RS), FEPAGRO, 1999.

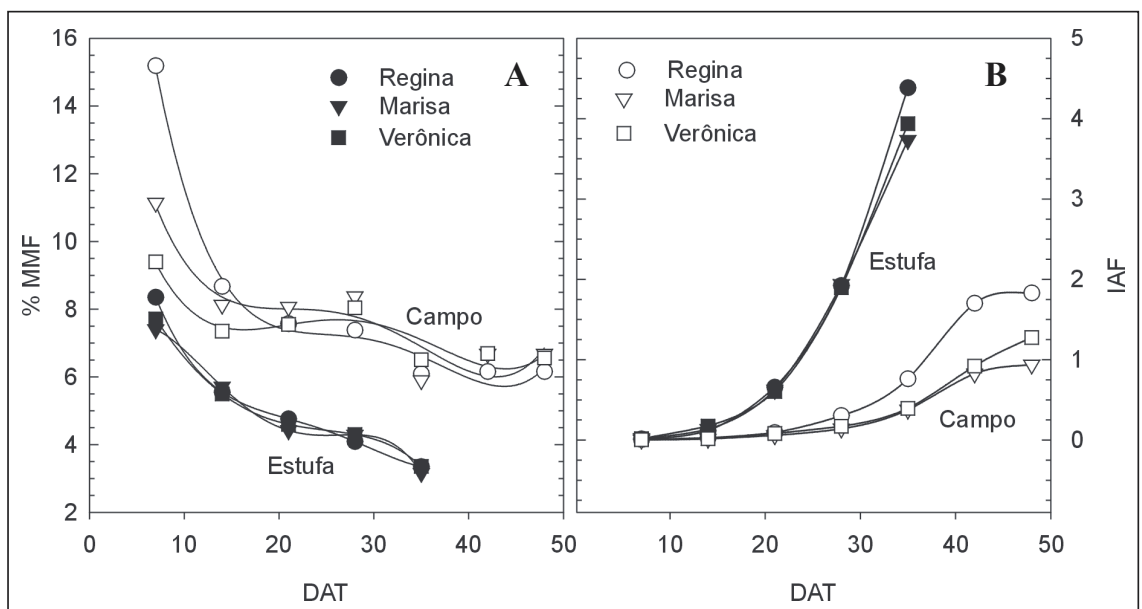

Figura 2. Percentagem de massa de matéria seca (\%MMS) (A) e índice de área foliar (IAF) (B) nas três cultivares de alface cultivadas em estufa e a campo em função de dias após o transplante (DAT). Eldorado do Sul (RS), FEPAGRO, 1999.

meira semana de cultivo. A variedade Regina apresentou IAF maior que as demais, as quais, não apresentaram diferença entre si (Figura 2B e Tabela 1).

Os dados obtidos para área foliar específica (AFE), que representa a área foliar pelo seu respectivo peso, indicaram que o ambiente da estufa também influencia este parâmetro (Figura 3B). Em estufa, onde ocorre menor disponibilidade de radiação solar incidente devido a redução de aproximadamente 


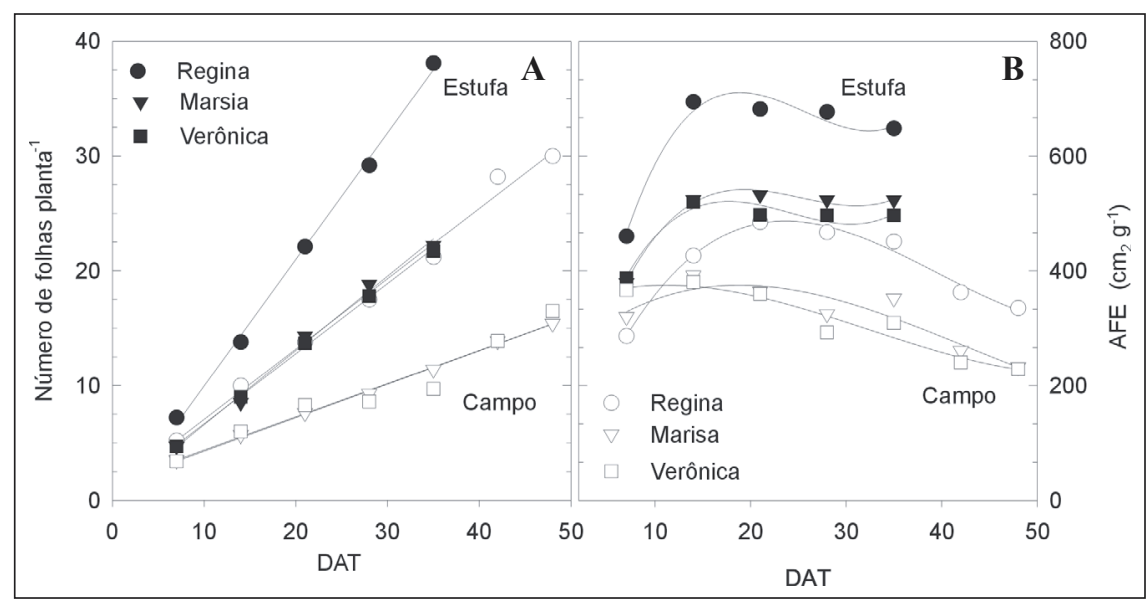

Figura 3. Número de folhas por planta (A) e área foliar específica (AFE) (B) de três cultivares de alface cultivadas em estufa e a campo em função de dias após o transplante (DAT). Eldorado do Sul (RS), FEPAGRO, 1999.

$30 \%$ pelo material de cobertura, a AFE foi maior. Isto está de acordo com resultados de Dale (1988), o qual observou que, o aumento de sombreamento resulta em folhas maiores mas, mais finas. Charles-Edwards (1979), também relata que folhas que tiveram sua expansão celular sob condições de baixa disponibilidade de radiação solar são mais finas, e tem maior superfície de área foliar do que folhas que se expandiram sob condições de alta disponibilidade de radiação solar. As oscilações da AFE que ocorrem ao longo do ciclo podem ser devido às variações da temperatura e da radiação solar. Segundo Carles-Edwards et al. (1986), a AFE de plantas de tomate e de crisântemo que cresceram em ambiente controlado foram correlacionadas com a temperatura média do ambiente. As duas culturas apresentaram aumento da AFE com o au- mento da temperatura enquanto que o aumento na disponibilidade de radiação solar resultou em decréscimos na AFE.

Em plantas de milho e de tomate que cresceram em condições de alta disponibilidade de radiação solar, a AFE pode decrescer por causa do acúmulo de amido nos cloroplastos com o decorrer do ciclo (Charles-Edwards et al., 1986). Com isso, pode-se inferir que o declínio da AFE com o decorrer do tempo poderia ser devido ao acúmulo de material estrutural e também ao envelhecimento das folhas.

Em síntese observou-se, no presente trabalho, que o cultivo em estufa acelera os parâmetros de crescimento de diferentes cultivares de alface, o que se reflete, principalmente, numa antecipação da colheita. Para as condições de campo observou-se um melhor desempenho da cultivar Regina, em relação às cultivares Marisa e Verônica.

\section{LITERATURA CITADA}

BERGAMASCHI, H.; GUADAGNIN, M. Agroclima da estação experimental agronômica da UFRGS. Porto Alegre, Faculdade de Agronomia, UFRGS, 1990.

CEASA. Disponível em http:// www.ceasars.gov.br. Acesso em novembro 2002. CERMEÑO, Z.S. Estufas - instalações e manejo. Lisboa. Litexa Editora, Ltda. 355 p. 1990.

CHARLES-EDWARDS, D.A. A model for leaf growth. Annals of Botany, London, v.44, p.523535, 1979.

CHARLES-EDWARDS, D.A.; DOLEY, D.; RIMMINGTON, G.M. Modelling plant growth and development. North Ryde: Academic Press, $1986.235 \mathrm{p}$.

CRAUFURD, P.Q.; SUBEDI, M.; SUMMERFIELD, R.J. Leaf appearance in Cowpea: Effects of temperature and photoperiod. Crop Science, Madison, v.37, p.167-171, 1997.

DALE, J.E. The control of leaf expansion. Annual Review of Plant Physiology and Plant Molecular Biology, Palo Alto, v.30, p.267-295, 1988.

DANTAS, R.T.; ESCOBEDO, J.F. Índices morfofisiológicos e rendimento da alface (Lactuca sativa L.) em ambientes natural e protegido. Revista Brasileira de Engenharia Agrícola e Ambiental, Campina Grande, v.2, n.1, p.27-31, 1998.

HERMES, C.C.; MEDEIROS, S.L.P.; MANFRON, P.A.; CARON, B.; POMMER, S.F.; BIANCHI, C. Emissão de folhas de alface em função de soma térmica. Revista Brasileira de Agrometeorologia, Santa Maria, v.9, n.2, p.269275, 2001.

SEGOVIA, J.F.O.; ANDRIOLO, J.L; BURIOL, G.A.; SCHNEIDER, F.M. Comparação do crescimento e desenvolvimento da alface (Lactuca sativa $\mathrm{L}$.) no interior e no exterior de uma estufa de polietileno em Santa Maria, RS. Ciência Rural, Santa Maria, v.27, n.1, p. 37-41, 1997.

TIBBITS, T.W.; BOTTEMBERG, G. Growth of lettuce under controlled humidity levels. Journal of the American Society of Horticultural Science. Mount Vernon, v.101, n.1, p.70-73, 1976. 